\title{
Prevalence and correlates of depression among chronic kidney disease patients in Taiwan
}

\author{
Hsin-Hung Chiang ${ }^{1 \dagger}$, Hanoch Livneh ${ }^{2 \dagger}$, Mei-Ling Yen ${ }^{1}$, Tsai-Chung Li ${ }^{3,4}$ and Tzung-Yi Tsai ${ }^{5,6,7^{*}}$
}

\begin{abstract}
Background: Chronic kidney disease (CKD) is a progressive disease that causes a permanent impairment of renal function and premature mortality. The associated prognosis may result in serious psychological distress to the affected individual. However, there are limited data on the psychological correlates, and in particular depression, in Chinese CKD patients. This study aimed to examine the prevalence of depression, as well as the influence of other psychosocial factors on depression, among Taiwanese CKD patients.

Methods: We used a cross-sectional research design to recruit 270 CKD patients who were not undergoing dialysis treatment at a hospital in southern Taiwan during 2011. The structured questionnaire used in this study gathered information on respondent demographic and disease characteristics, and information obtained from the Taiwanese Depression Questionnaire. Factors associated with depression were examined by a multiple logistic regression analysis.

Results: The crude and age-standardized prevalence of depression were $22.6 \%$ and $20.6 \%$, respectively. Those who had sleep disturbances, reported having no religious beliefs, followed no regular exercise regimen, and were diagnosed with stage III or above CKD demonstrated a significantly higher risk of depression.

Conclusion: Our findings are beneficial to healthcare providers, as they identify both the prevalence of depression and several of its correlates. By identifying CKD patients with a higher risk of depression, healthcare providers may be better able to ensure the provision of appropriate rehabilitation to this population.
\end{abstract}

Keywords: Depression, Chronic kidney disease, Prevalence, Taiwan

\section{Background}

Chronic kidney disease (CKD) is becoming a major public health concern. The worldwide prevalence of endstage renal disease (ESRD) is expected to continue to rise at an annual rate of $7 \%$ and exceed 2 million by 2010, which will cost about 1.1 trillion dollars in medical expenditures [1]. Recently, based on a report by the United States Renal Data System published in 2007, Taiwan had the highest incidence and prevalence rate of ESRD patients globally, with 415 and 2288 per million populations, respectively [2]. The soaring number of patients with renal disease resulted in a heavy economic burden to the healthcare system. According to a report

\footnotetext{
* Correspondence: dm732024@tzuchi.com.tw

${ }^{+}$Equal contributors

${ }^{5}$ Department of Medical Research, Buddhist Dalin Tzu Chi General Hospital, Chiayi, Taiwan

${ }^{6}$ Department of Nursing, Tzu Chi College of Technology, Hualien, Taiwan Full list of author information is available at the end of the article
}

by the Taiwan National Department of Health published in 2009, the number of ESRD patients only accounted for $0.2 \%$ of all beneficiaries, but consumed 32.8 billion NTD (New Taiwan Dollar), which is approximately 7.1\% of the entire Medicare budget, and surpasses the medical expenditures on cancer (18.3 billion NTD) [3].

CKD not only causes enormous economic losses, but also triggers major challenges in regards to health. Wen and colleague [4] found that CKD patients had an 83\% higher rate of all-cause mortality and were twice as likely to die from cardiovascular disease. Due to the irreversible nature and poorer prognostic outcomes, psychiatric disorders, in particular depression, are frequently common among patients with renal disease [5-7]. One study found that ESRD patients have a nearly 4-fold higher risk for depression than the general population [8]. One cause of concern was that depression not only elevated the length of hospitalization by $30 \%$ [9], but also more

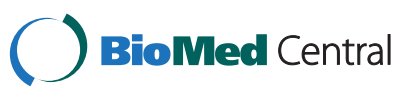


than doubled the likelihood of mortality in ESRD patients with depression compared to those with ESRD only [8]. However, in contrast to available data on ESRD, there is a limited amount of information regarding depression among patients with earlier stages of CKD. Recently, a study demonstrated that depression in CKD patients, who were not receiving dialysis treatment, was linked to a $86 \%$ higher risk of adverse events including death, early dialysis initiation or hospitalization risk [10], suggesting that depression is a matter of great concern during the routine care of CKD patients.

Although some studies on depression and its contributing factors among CKD patients have been conducted, the majority of the studies were performed in Western countries [10-12]. Influenced by the Asian conservative culture, Chinese often regard depression as a taboo and are, thus, highly reluctant to mention this openly to others [13]. Thus, a review of the literature indicates that most reports on Taiwanese CKD patients have focused on the effects of medical treatment [14], self-care behaviours [15], and possible pathogenic factors [16]. Conversely, research findings on depression among Chinese CKD patients are scarce. This study aimed to examine the prevalence of depression and related correlates among Taiwanese CKD patients, with the hope that findings may suggest appropriate psychological intervention strategies for Asian CKD patients.

\section{Methods}

\section{Study design and population}

This cross-sectional study adopted a purposive participant recruitment and was carried out at a hospital in southern Taiwan to recruit CKD patients who were not undergoing dialysis treatment from either outpatient or inpatient departments between January and August of 2011. The inclusion criteria were as follows: (i) being 20 years of age or older; (ii) having no cognitive impairments and being able to express opinion in either Mandarin or Taiwanese; (iii) being aware of their CKD and not yet undergoing dialysis treatment; and (iv) being able to consent to a blood test on the survey date. The sample size needed for the study was estimated by using the methodology of Hsieh et al. [17], where $\alpha$ was set to 0.05 , power was set to 0.8 , the event rate at mean of $\mathrm{X}$ was set to 0.03 [4], and the odds ratio of 3.56 per unit increase in $\mathrm{X}$ [18]. It was determined, based on these psychometrics, that a sample of at least 167 patients was required for data analysis.

\section{Instruments}

A set of measures was used for data collection. These included the Taiwanese Depression Questionnaire (TDQ), and an additional questionnaire that obtained information on demographic and disease characteristics.
The TDQ, developed by Lee et al. [19], was chosen, as it was specifically created with the Asian culture in mind. It consists of 18 items, each addresses those symptoms that have been experienced over the past week using a scale of 0 (absence of symptoms) to 3 (presence of symptoms almost every day) scores. Total scale scores, therefore, can theoretically range from 0 (low depression) to 54 (high depression). After using the Structured Clinical Interview for DSM Disorders (SCID) manual as the gold standard, the TDQ was shown to have good concurrent validity, with the area under the Received Operating Characteristic (ROC) curve being 0.92. The TDQ also performed optimally, at a cutoff value of 19 or greater, in detecting the presence of depressive symptoms, whether for patients with kidney disease or for the general population [19-21]. In regards to its reliability, the TDQ has previously demonstrated good internal consistency among different groups of subjects, with a Cronbach's $\alpha$ ranging between 0.90 and $0.92[13,20,21]$. The Cronbach's $\alpha$ derived from the present data yielded a coefficient of 0.89 .

The second part of the questionnaire contained information on demographic and disease characteristics, developed from previous literature and clinical experiences. Information on patients' demographic data included gender, age, marital status, educational level, job status, living status, religious beliefs, and certain lifestyle factors, such as smoking, alcohol consumption, exercise habits, and sleep disturbance. Those who answered "currently" or "yes/past" to smoking were classified as smokers. Alcohol consumption was stratified into two groups based on whether they had consumed alcohol at least two times per week. Those who exercised 3, or more, days per week were classified as having regular exercise habits. As for information about sleep disturbances, to be congruent with the timeframe used for data collection, it was obtained by a single question that asked participants how often they have awakened suddenly from sleep during the past week. Those who have been awakened more than twice per week were classified as having sleeping problems. The disease characteristics included the following: chronic disease (i.e. at least one of the following: diabetes mellitus, hypertension, heart disease, or a stroke), CKD stage, disease duration of CKD, hemoglobin level, creatinine level, and albumin level. All disease characteristics were obtained from reviews of the patients' charts.

\section{Data collection}

This study was approved by the Institutional Review Board of Buddhist Dalin Tzu Chi General Hospital. The researchers explained the purpose of the study and its procedures to all of the patients. Informed consent was obtained after the patients understood and agreed to 
participate in the study. During the completion of the questionnaires, the researchers were available to answer any inquiries regarding the questionnaires. For illiterate patients, the researchers read them the questionnaires and recorded their answers. The questionnaires were returned without any identifying personal information. Patients were assured of complete confidentiality with respect to all of the obtained data. Patients were given the option to withdraw from the study at any time without any penalty.

\section{Statistical analysis}

Descriptive and inferential statistical analyses were conducted in accordance with the study aims and the nature of variables. For descriptive analysis, subjects were grouped according to the presence of depression (i.e. cut off score of $\geq 19$ ). Differences between groups on the various study variables were expressed in terms of means and the standard deviation (SD) or in percentage. Aside from age, disease duration and blood biochemistry markers that were expressed in means and SD, categorical variables were expressed as percentages. For inferential analysis, a $t$-test or chi-square test were used to explore the relationship between the study's variables and depression. Multiple logistic regression analysis was further used to determine the various correlates and their adjusted odds ratios (AOR), in predicting the existence of depression. All analyses were conducted with SPSS version 12.0 (SPSS, Inc., Chicago, IL). A p $<0.05$ was considered statistically significant.

\section{Results}

Demographic data and disease characteristics of CKD patients

A total of 270 CKD patients were recruited during the period of data collection. Of these, 61 individuals met the criteria for depression based on the TDQ total score of $\geq 19$, which translates to a crude prevalence of $22.6 \%$ (61/270). After adjusting for age, based on the percentages of the 2000 World Standard Population, the agestandardized depression prevalence was found to be $20.6 \%$. Thus, it was estimated that about one out of five CKD patients met the criteria for depression in our study.

In the present study, the mean age of the subjects was 64.5 years $(\mathrm{SD}=12.13)$, and most of the subjects were male (61.1\%), married (93.0\%), unemployed (73.0\%), and cohabitating (91.1\%). Additionally, most subjects reported having religious beliefs (84.4\%), had a low level of education (74.8\%), experienced sleep disturbances (63.0\%), regularly engaged in exercise (64.1\%), and had low level of alcohol consumption (94.1\%). Nearly $60 \%$ of the patients were non-smokers. Furthermore, the mean disease duration of CKD was 3.53 years, and most patients presented with a CKD Stage IV or above (60.7\%), as well as other chronic diseases (65.6\%). The mean levels of albumin, hemoglobin, and creatinine were $3.51 \mathrm{~g} / \mathrm{dl}$, $11.08 \mathrm{~g} / \mathrm{dl}$, and $5.05 \mathrm{mg} / \mathrm{dl}$, respectively (Table 1 ).

\section{Correlations among demographic data, disease characteristics, and depression}

Table 2 presented the demographic and disease characteristics among CKD patients who met criteria for depression and for those who did not. The results from the univatiate analysis revealed that CKD patients who were depressed were also more likely to be female $(p=0.03)$, single $(\mathrm{p}=0.04)$, living alone $(\mathrm{p}=0.02)$, reported no religious beliefs $(p=0.01)$, experienced sleep disturbance $(\mathrm{p}<0.01)$, and did not engage in regular exercise $(\mathrm{p}=0.03)$. Moreover, those with CKD stage IV or above tended to be more depressed $(\mathrm{p}=0.02)$.

\section{Predictor of depression in CKD patients}

Multiple logistic regression analysis indicated that religious beliefs, sleep disturbances, exercise habits, and disease stage were significantly related to depression in these CKD patients. Compared to patients with religious beliefs, those with no religious beliefs had a 2.56-fold higher risk of depression (95\% confidence interval (CI): 1.24-5.27). The risk for depression among patients with sleep disturbances was higher than for those with no sleep disturbance (AOR: 3.01; 95\% CI: 1.37-6.62). CKD patients who did not engage in exercise had a significantly higher AOR for depression (AOR: 2.12; 95\% CI: 1.14-3.96). Those diagnosed with CKD stage IV or higher were more than twice as likely to have depression (AOR: 2.14; 95\% CI: 1.04-4.40) (Table 3).

\section{Discussion}

To the best of our knowledge, there are no studies that have reported the prevalence of depression, along with its influencing factors, among Chinese CKD patients. This study found that the crude and age-adjusted prevalence of depression were $22.6 \%$ and $20.6 \%$, respectively, revealing that one out of five CKD patients met the criteria for depressive disorders. This finding corraborates the $20 \%$ to $26 \%$ prevalence of depression found among renal disease patients who had received dialysis treatment [10-12]. It was inferred that CKD gradually induces fatigue, nausea, and loss of energy [22]. Furthermore, the changes in body image and inconvenience resulting from subsequent dialysis treatment may also heighten the level of depression in CKD patients [23]. Despite the fact that depression is increasingly prevalent among CKD patients, its detection and management are still not recognized in routine care [12]. Most importantly, a large number of Asian individuals view 
Table 1 Demographic and disease characteristics of participants $(n=270)$

\begin{tabular}{|c|c|c|}
\hline Variables & $M(S D)$ & $n(\%)$ \\
\hline \multicolumn{3}{|l|}{ Demographic data } \\
\hline Age (years) & $64.5 \pm 12.13$ & \\
\hline \multicolumn{3}{|l|}{ Gender } \\
\hline Male & & 165(61.1) \\
\hline Female & & 105(38.9) \\
\hline \multicolumn{3}{|l|}{ Marital status } \\
\hline Single & & 19(7.0) \\
\hline Married (or divorced) & & 251(93.0) \\
\hline \multicolumn{3}{|l|}{ Educational level } \\
\hline Low (< 12th grade) & & $202(74.8)$ \\
\hline High ( $\geq 12$ th grade) & & $68(25.2)$ \\
\hline \multicolumn{3}{|l|}{ Job } \\
\hline Employed & & $73(27.0)$ \\
\hline Unemployed & & 197(73.0) \\
\hline \multicolumn{3}{|l|}{ Living status } \\
\hline Living alone & & $24(8.9)$ \\
\hline Cohabitating & & 246(91.1) \\
\hline \multicolumn{3}{|l|}{ Religious beliefs } \\
\hline Yes & & $228(84.4)$ \\
\hline No & & $42(15.6)$ \\
\hline \multicolumn{3}{|l|}{ Sleep disturbance } \\
\hline Yes & & $170(63.0)$ \\
\hline No & & $100(37.0)$ \\
\hline \multicolumn{3}{|l|}{ Alcohol drinking } \\
\hline Low( $\leq 1$ times/week) & & 254(94.1) \\
\hline High( $\geq 2$ times/week) & & $16(5.9)$ \\
\hline \multicolumn{3}{|l|}{ Cigarette smoking } \\
\hline Yes & & $111(41.1)$ \\
\hline No & & 159(58.9) \\
\hline \multicolumn{3}{|l|}{ Regular exercise } \\
\hline Yes & & $173(64.1)$ \\
\hline No & & 97(35.9) \\
\hline \multicolumn{3}{|l|}{ Disease characteristics } \\
\hline Disease duration (years) & $3.53 \pm 2.85$ & \\
\hline \multicolumn{3}{|l|}{ CKD stage } \\
\hline Stage III and below & & 106(39.3) \\
\hline Stage IVand above & & $164(60.7)$ \\
\hline \multicolumn{3}{|l|}{ Other Chronic diseases } \\
\hline$\leq 1$ & & 93(34.4) \\
\hline$\geq 2$ & & 177(65.6) \\
\hline Hemoglobin (g/dl) & $11.08 \pm 2.03$ & \\
\hline Creatine(mg/dl) & $5.05 \pm 1.81$ & \\
\hline Albumin(g/dl) & $3.51 \pm 0.31$ & \\
\hline
\end{tabular}

depression as a taboo and do not openly seek regular psychotherapy [24]. Therefore, healthcare providers must be cognizant of the existence of depression among CKD patients and inform them by standard care procedures to avoid possible embarrassment and discomfort when implementing early screening to identify and refer high risk cases $[11,25]$.

With respect to the correlates of depression, the results of the multiple logistic analysis indicated that patients' sex, age and marital status were not associated with depression among CKD patients, echoing previous findings $[11,12,21]$. The failure to observe any link between patients' age and depression may also be partly due to the restricted age range of the participants and their older age $(M=64.5$ years $)$. Additionally, we found that living alone was not associated with an increased risk of depression. Despite the lack of comparable studies, the relationship between one's living status and depression approached borderline significance. Further studies are still warranted to clarify the relationship between them. In regards to religious beliefs, patients with no religious beliefs were 2.5 times more likely to experience depression than those who reported having religious beliefs. It is possible that patients with religious beliefs had the opportunity to associate with other people and this experience may enhance psychological support, provide comfort through religious and spiritual counseling, and help relieve psychological pressures [26]. Our findings, however, differed from those reported by Chen et al. [21]. This inconsistency may be associated with the differences in the study participants (i.e. all subjects were hemodialysis patients in Chen et al. study) and statistical analysis methods (Chen et al. relied solely on univariate analysis). Using only univariate analysis to assess the relationship between religion and depression, instead of adopting a more comprehensive multivariate model that controls for potentially intervening covariates, may not accurately reflect the relationship between religion and depression.

This study also revealed that those with sleep disorders were three times more likely to have depression than those with no sleep problems. Despite the paucity of findings on the relationships between sleep disorders and depression among CKD patients, this finding is consistent with the theory that insomnia was related to the risk of depression in the general population [27]. From a neurobiological perspective, the arousal system of individuals who experience insomnia was more active than in those of the general population. This phenomenon would cause altered corticothalamic activities, such as higher concentrations of adrenocorticotropin (ACTH) and cortisol, which might further predispose them to develop psychiatric disorders $[27,28]$. Therefore, it could be suggested that periodic assessment of sleep disorders 
Table 2 Relationship between demographic data, disease characteristics and depression risk $(n=270)$

\begin{tabular}{|c|c|c|c|c|}
\hline Variables & Depress $(n=61)$ & Non-depress $(n=209)$ & $t / x^{2}$ & $p$ \\
\hline \multicolumn{5}{|l|}{ Demographic data } \\
\hline Age (Mean $\pm S D)$ (years) & $65.70 \pm 12.37$ & $63.87 \pm 14.78$ & 0.95 & 0.34 \\
\hline \multicolumn{5}{|l|}{ Gender } \\
\hline Male & $30(49.2)$ & 135(64.6) & \multirow{2}{*}{4.72} & \multirow{2}{*}{0.03} \\
\hline Female & $31(50.8)$ & 74(35.4) & & \\
\hline \multicolumn{5}{|l|}{ Marital status } \\
\hline Single & $8(13.1)$ & $11(5.3)$ & \multirow{2}{*}{4.45} & \multirow{2}{*}{0.04} \\
\hline Married (or divorced) & $53(86.9)$ & 198(94.7) & & \\
\hline \multicolumn{5}{|l|}{ Educational level } \\
\hline Low (<12th grade) & $45(73.8)$ & 157(75.1) & \multirow{2}{*}{0.05} & \multirow{2}{*}{0.83} \\
\hline High ( $\geq 12$ th grade) & $16(26.2)$ & $52(24.9)$ & & \\
\hline \multicolumn{5}{|l|}{ Job } \\
\hline Employed & $11(82.0)$ & $62(29.7)$ & \multirow{2}{*}{3.24} & \multirow{2}{*}{0.07} \\
\hline Unemployed & $50(18.0)$ & $147(70.3)$ & & \\
\hline \multicolumn{5}{|l|}{ Living status } \\
\hline Living alone & $10(16.4)$ & $14(6.7)$ & \multirow{2}{*}{5.48} & \multirow{2}{*}{0.02} \\
\hline Cohabitating & $51(83.6)$ & 195(93.3) & & \\
\hline \multicolumn{5}{|l|}{ Religious beliefs } \\
\hline Yes & $45(73.8)$ & 183(87.6) & \multirow{2}{*}{6.83} & \multirow{2}{*}{0.01} \\
\hline No & $16(26.2)$ & $26(12.4)$ & & \\
\hline \multicolumn{5}{|l|}{ Sleep disturbance } \\
\hline Yes & $48(78.7)$ & $122(41.6)$ & \multirow{2}{*}{8.36} & \multirow{2}{*}{$<0.0$} \\
\hline No & $13(21.3)$ & $87(58.4)$ & & \\
\hline \multicolumn{5}{|l|}{ Alcohol drinking } \\
\hline Low( $\leq 1$ times/week) & $55(90.2)$ & 199(95.2) & \multirow{2}{*}{2.16} & \multirow{2}{*}{0.14} \\
\hline $\operatorname{High}(\geq 2$ times/week) & $6(9.8)$ & $10(4.8)$ & & \\
\hline Cigarette smoking & & & & \\
\hline Yes & $21(34.4)$ & $90(43.1)$ & 146 & 073 \\
\hline No & $40(65.6)$ & 119(56.9) & 1.70 & $0.2 J$ \\
\hline Regular exercise & & & & \\
\hline Yes & $32(52.5)$ & 142(67.9) & & \\
\hline No & $29(47.5)$ & $67(32.1)$ & T. & 0.03 \\
\hline Disease characteristics & & & & \\
\hline Disease duration (Mean $\pm \mathrm{SD}$ ) (years) & $4.04 \pm 3.26$ & $3.38 \pm 2.70$ & -1.44 & 0.15 \\
\hline CKD stage & & & & \\
\hline Stage III and below & $16(26.2)$ & $90(43.1)$ & 561 & בחمO \\
\hline Stage IVand above & $45(73.8)$ & 119(56.9) & (1) & 0.02 \\
\hline Other Chronic diseases & & & & \\
\hline$\leq 1$ & $16(26.2)$ & $77(36.8)$ & 236 & 013 \\
\hline$\geq 2$ & $45(73.8)$ & $132(63.2)$ & 2.00 & 0.10 \\
\hline Hemoglobin $(\mathrm{g} / \mathrm{dl})$ & $10.71 \pm 2.03$ & $11.18 \pm 2.02$ & 1.60 & 0.11 \\
\hline Creatine(mg/dl) & $5.40 \pm 3.82$ & $4.95 \pm 4.28$ & -0.5 & 0.60 \\
\hline Albumin(g/dl) & $3.50 \pm 0.62$ & $3.51 \pm 0.48$ & 0.04 & 0.97 \\
\hline
\end{tabular}




\begin{tabular}{|c|c|c|}
\hline Variables & Crude OR $(95 \% \mathrm{CI})$ & Adjusted OR (95\% CI) \\
\hline \multicolumn{3}{|l|}{ Gender } \\
\hline Male & 1 & 1 \\
\hline Female & $1.88(1.06-3.36)$ & $1.64(0.85-3.17)$ \\
\hline \multicolumn{3}{|l|}{ Marital status } \\
\hline Single & $2.72(1.04-7.09)$ & $1.09(0.25-4.80)$ \\
\hline Married (or divorced) & 1 & 1 \\
\hline \multicolumn{3}{|l|}{ Living status } \\
\hline Living alone & $2.73(1.15-6.49)$ & $3.07(0.81-11.62)$ \\
\hline Cohabitating & 1 & 1 \\
\hline \multicolumn{3}{|l|}{ Religious beliefs } \\
\hline Yes & 1 & 1 \\
\hline No & $2.50(1.24-5.05)$ & $2.56(1.24-5.27)^{* *}$ \\
\hline \multicolumn{3}{|l|}{ Sleep disturbance } \\
\hline Yes & $2.63(1.35-5.15)$ & $3.01(1.37-6.62)^{*}$ \\
\hline No & 1 & 1 \\
\hline \multicolumn{3}{|l|}{ Regular exercise } \\
\hline Yes & 1 & 1 \\
\hline No & $2.24(1.25-4.01)$ & $2.12(1.14-3.96)^{*}$ \\
\hline \multicolumn{3}{|l|}{ CKD stage } \\
\hline Stage III and below & 1 & 1 \\
\hline Stage IVand above & $2.13(1.13-4.01)$ & $2.14(1.04-4.40)^{*}$ \\
\hline
\end{tabular}

in CKD patients could be of utmost clinical importance to reduce the risk of depression.

Individuals who did not exercise had higher odds of developing depression than those who did, echoing a previous study [11]. Two reasons may account for this result. First, those who exercise regularly are able to strengthen their social network, thereby having more resources with which to face the impact of the disease. Second, a former study had reported that exercise could increase the concentration of certain monoamine neurotransmitters, such as serotonin, norepinephrine and dopamine [29], which may stimulate the brain to produce endorphins that help the individual feel happier and more relaxed [30]. However, Johansen et al. [31] found that over $60 \%$ of healthcare providers do not assess the exercise patterns or recommend appropriate exercise programs for patients with renal disease. Healthcare providers should design a personalized exercise program based on the patient's level of physical functioning, including activities such as walking, tai-chi, yoga, or swimming, to delay the deterioration of renal function and further relieve stress associated with the disease [32]. Furthermore, these exercises were also recommended to be integrated into the home-based or dialysis-based training programs which may be beneficial in increasing the motivation levels of individuals with CKD to engage in exercise, thus decreasing the risk of depression [33].

The findings of our study also show that the more advanced the stage of kidney disease, the more likely the patient is to demonstrate a depressive mood. This finding differs from a report of Hedayati et al. [12]. It could be speculated that these conflicting findings are due to differences in the measurement tools and classifications used. For example, Hedayati et al. [12] used the Mini International Neuropsychiatric Interview Tool to examine the prevalence of depressive episodes, which was distinct from our scale (TDQ). Furthermore, the study by Hedayati et al. classified CKD by four stages (from stage II to stage V), which was also different from the classification system used in our study. Nevertheless, as it relates to disease stage, patients with more advanced stages of kidney disease typically experience a large number of symptoms [6]. The dread associated with entering dialysis treatment and the anxiety over one's changing health status may further aggravate depression [34]. Therefore, it is imperative for healthcare providers to periodically evaluate the emotional status of CKD patients with more advanced stages (i.e. stage IV or above).

The results of this study should be interpreted with the following limitations in mind. First, the study subjects were recruited from a single hospital, which may limit the generalizability of the findings and, therefore, these findings cannot represent the depressive symptoms of all Chinese CKD patients, and certainly not of non-Chinese populations. This limitation, however, is not unique to our study. By their very nature, most studies are limited by such factors as subjects' ethnicity, geographical location, nationality and the nature of the medical data available (e.g., levels of severity, functionality, symptomatology, duration of condition). Future studies should be conducted in a variety of regions of the country to examine if the findings are replicated within different demographic and geographic groups. Nonetheless, we calculated a required sample size analysis to ensure statistical power before embarking on the study, and thus the sample size used in this study may be considered satisfactory for exploring the factors associated with depression in CKD patients. Second, since this study used a cross-sectional design, we cannot infer causality from our findings. A longitudinal research design is needed to examine any causal relationships among the factors assessed in this study, such as pro-inflammatory cytokines. Third, the self-reported depressive symptoms yielded by the TDQ may differ from those observed by a trained physician, so the present findings should be interpreted with caution. Fourth, the sleep disturbance was only examined with a single-item question and therefore its psychometric characteristic may be suspect and, accordingly, must be interpreted 
cautiously. Despite these methodological concerns, to our knowledge, this was the first study to review the epidemiology of depression among Chinese CKD patients who were not treated by dialysis, a fact which can be useful in developing an early therapeutic regimen for Asian CKD patients.

\section{Conclusion}

Modern medical technology can effectively extend the survival rate of patients with chronic diseases. However, the physical and mental distress that results from disease symptoms and their treatment may induce negative mood in the patient. In the present study, we found that the crude and age-standardized prevalence of depression among CKD patients were $22.6 \%$ and $20.6 \%$, respectively. Patients with no religious beliefs, who did not regularly exercise, who had sleep disorders, and who were diagnosed with CKD stage IVor above, appeared to have a higher risk of developing depression. Healthcare providers should consider these findings as a reference for designing a standard rehabilitation program for CKD patients. Ensuring that mental health services are available to patients with CKD may be important first step to help them better psychologically adapt to their disease and possibly as important as improving the survival rate of patients with this chronic and life threatening disease.

\section{Abbreviations \\ CKD: Chronic kidney disease; ESRD: End-stage renal disease; NTD: New Taiwan dollar; TDQ: Taiwanese depression questionnaire; SCID: Structured clinical interview for DSM disorders; ROC: Received operating characteristic; SD: Standard deviation; AOR: Adjusted odds ratio; Cl: Confidence interval; ACTH: Adrenocorticotropin.}

\section{Competing interests}

The authors declare that they have no competing interests.

\section{Authors' contributions}

HHC provided administrative support and participated in providing comments on the manuscript drafts. $\mathrm{HL}$ contributed to the interpretation of data and providing comments on the final draft of the manuscript. MLY was responsible for data collection. $\mathrm{TCL}$ provided the statistical expertise and comments on the manuscript drafts. TYT was responsible for the study conception, design, data analysis, and drafting of the work. All authors read and approved the final manuscript.

\section{Acknowledgements}

This study was supported by grants from the Buddhist Dalin Tzu Chi General Hospital (DTCRD100-I-19). We thank to co-investigator of this project and the patients who respond our survey. $\mathrm{HHC}$ and $\mathrm{HL}$ have equal contribution for this paper.

\footnotetext{
Author details

${ }^{1}$ Department of Nursing, Buddhist Dalin Tzu Chi General Hospital, Chiayi, Taiwan. ${ }^{2}$ Rehabilitation Counseling Program, Portland State University, Portland, USA. ${ }^{3}$ Graduate Institute of Biostatistics, College of Public Health, China Medical University, Taichung, Taiwan. ${ }^{4}$ Department of Healthcare Administration, College of Health Science, Asia University, Taichung, Taiwan. ${ }^{5}$ Department of Medical Research, Buddhist Dalin Tzu Chi General Hospital, Chiayi, Taiwan. ${ }^{6}$ Department of Nursing, Tzu Chi College of Technology, Hualien, Taiwan. ${ }^{7}$ Department of Environmental and Occupational Health, College of Medicine, National Cheng Kung University, Tainan, Taiwan.
}

Received: 26 July 2012 Accepted: 22 March 2013

Published: 4 April 2013

\section{References}

1. Lysaght MJ: Maintenance dialysis population dynamics: current trends and long-term implications. J Am Soc Nephrol 2002, 13:S37-S40.

2. United States Renal Data System: Chapter 12: International Comparisons. http://www.usrds.org/2011/pdf/v2_ch012_11.pdf.

3. Bureau of National Health Insurance of Department of Health: Medical care payment. 2012. http://www.nhi.gov.tw/Resource/webdata/Attach_14261_2_97\% E9\%86\%AB\%E7\%99\%82\%E7\%B5\%A6\%E4\%BB\%98-ch.pdf.

4. Wen CP, Cheng TY, Tsai MK, Chang YC, Chan HT, Tsai SP, Chiang PH, Hsu CC, Sung PK, Hsu YH, Wen SF: All-cause mortality attributable to chronic kidney disease: a prospective cohort study based on 462,293 adults in Taiwan. Lancet 2008, 371:2173-2182.

5. Bossola M, Ciciarelli C, Stasio D, Conte GL, Vulpio C, Luciani G, Tazza L: Correlates of symptoms of depression and anxiety in chronic hemodialysis patients. Gen Hosp Psychiatry 2010, 32:125-131.

6. Cukor D, Cohen SD, Peterson RA, Kimmel PL: Psychosocial aspects of chronic disease: ESRD as a paradigmatic illness. J Am Soc Nephrol 2007, 18:3042-3055.

7. Chilcot J, Wellsted D, Farrington K: Depression in end-stage renal disease: current advances and research. Semin Dial 2010, 23:74-82.

8. Hedayati SS, Bosworth HB, Briley LP, Sloane RJ, Pieper CF, Kimmel PL, Szczech LA: Death or hospitalization of patients on chronic hemodialysis is associated with a physician-based diagnosis of depression. Kidney Int 2008, 74:930-936.

9. Hedayati SS, Grambow SC, Szczech LA, Stechuchak KM, Allen AS, Bosworth HB: Physician-diagnosed depression as a correlate of hospitalizations in patients receiving long-term hemodialysis. Am J Kidney Dis 2005, 46:642-649.

10. Hedayati SS, Minhajuddin AT, Afshar M, Toto RD, Trivedi MH, Rush AJ: Association between major depressive episodes in patients with chronic kidney disease and initiation of dialysis, hospitalization, or death. JAMA 2010, 303:1946-1953.

11. Fischer MJ, Kimmel PL, Greene T, Gassman JJ, Wang X, Brooks DH, Charleston J, Dowie D, Thornley-Brown D, Cooper LA, Bruce MA, Kusek JW, Norris KC, Lash JP, AASK study group: Sociodemographic factors contribute to the depressive affect among African Americans with chronic kidney disease. Kidney Int 2010, 77:1010-1019.

12. Hedayati SS, Minhajuddin AT, Toto RD, Morris DW, Rush AJ: Prevalence of major depressive episode in CKD. Am J Kidney Dis 2009, 54:424-432.

13. Liu CN: The association of depressive symptoms with socioeconomic status, general health conditions, and health behaviors in communitydwelling adults. Taiwan J Public Health 2009, 28:300-311.

14. Huang CC, Cheng KF, Wu HD: Survival analysis: comparing peritoneal dialysis and hemodialysis in Taiwan. Perit Dia Int 2008, 28:S15-S20.

15. Weng LC, Dai YT, Huang HL, Chiang YJ: Self-efficacy, self-care behaviours and quality of life of kidney transplant recipients. J Adv Nurs 2010, 66:828-838.

16. Tsai SY, Tseng HF, Tan HF, Chien YS, Chang CC: End-stage renal disease in Taiwan: a case-control study. J Epidemiol 2009, 19:169-176.

17. Hsieh FY, Bloch DA, Larsen MD: A simple method of sample size calculation for linear and logistic regression. Stat Med 1998, 17:1623-1634.

18. Egede LE: Major depression in individuals with chronic medical disorders: prevalence, correlates and association with health resource utilization, lost productivity and functional disability. Gen Hosp Psychiatry 2007, 29:409-416.

19. Lee Y, Yang MJ, Lai TJ, Chiu NM, Chau TT: Development of the Taiwanese depression questionnaire. Chang Gung Medl J 2000, 23:688-694.

20. Lee Y, Lin PY, Hsu ST, Cing-Chi Y, Yang LC, Wen JK: Comparing the use of the Taiwanese depression questionnaire and beck depression inventory for screening depression in patients with chronic pain. Chang Gung Med J 2008, 31:369-377.

21. Chen YS, Wu SC, Wang SY, Jaw BS: Depression in chronic haemodialysed patients. Nephrology 2003, 8:121-126.

22. Hedayati SS, Finkelstein FO: Epidemiology, diagnosis, and management of depression in patients with CKD. Am J Kidney Dis 2009, 54:741-752.

23. Son YJ, Choi KS, Park YR, Bae JS, Lee JB: Depression, symptoms and the quality of life in patients on hemodialysis for end-stage renal disease. Am J Nephrol 2009, 29:36-42. 
24. Yeh $\mathrm{YH}$, Lin JCH: A questionnaire study of depression related helpseeking behavior among the general public in Taiwan. Formosa J Men Health 2006, 19:125-148.

25. Finkelstein FO, Wuerth D, Troidle LK, Finkelstein SH: Depression and endstage renal disease: a therapeutic challenge. Kidney Int 2008, 74:843-845.

26. Çoruh B, Ayele H, Pugh M, Mulligan T: Does religious activity improve health outcomes? A critical review of the recent literature. Explore 2005, 1:186-191.

27. Neckelmann D, Mykletun A, Dahl AA: Chronic insomnia as a risk factor for developing anxiety and depression. Sleep 2007, 30:873-880.

28. Baglioni C, Battagliese G, Feige B, Spiegelhalder K, Nissen C, Voderholzer U, Lombardo C, Riemann D: Insomnia as a predictor of depression: a metaanalytic evaluation of longitudinal epidemiological studies. $J$ Affect Disord 2011, 135:10-19.

29. Ploughman M: Exercise is brain food: the effects of physical activity on cognitive function. Dev Neurorehabil 2008, 11:236-240.

30. Koehl M, Meerlo P, Gonzales D, Rontal A, Turek FW, Abrous DN: Exerciseinduced promotion of hippocampal cell proliferation requires $\beta$ endorphin. FASEB J 2008, 22:2253-2262

31. Johansen KL, Sakkas GK, Doyle J, Shubert T, Dudley RA: Exercise counseling practices among nephrologists caring for patients on dialysis. Am J Kidney Dis 2003, 41:171-178.

32. Smith $A C$, Burton JO: Exercise in Kidney disease and diabetes: time for action. J Ren Care 2012, 38:52-58.

33. Johansen KL: Exercise and chronic kidney disease: current recommendations. Sports Med 2005, 35:485-499.

34. Kimmel PL: Depression in patients with chronic renal disease: what we know and what we need to know. J Psychosom Res 2002, 53:951-956.

doi:10.1186/1471-2369-14-78

Cite this article as: Chiang et al:: Prevalence and correlates of depression among chronic kidney disease patients in Taiwan. BMC Nephrology 2013 14:78.

\section{Submit your next manuscript to BioMed Central and take full advantage of:}

- Convenient online submission

- Thorough peer review

- No space constraints or color figure charges

- Immediate publication on acceptance

- Inclusion in PubMed, CAS, Scopus and Google Scholar

- Research which is freely available for redistribution 